\title{
Learning to Connect: a Training Model for Public Sector on Advanced E-Government Services and Inter-Organizational Cooperation
}

\author{
http://dx.doi.org/10.3991/ijac.v7i1.3577 \\ N. Casalino \\ Guglielmo Marconi University, Rome, Italy
}

\begin{abstract}
Accomplishing interoperability among public information systems is a complex task not only by the variety of technological specifications and by the nature of the organisations in which the systems are implemented, but also because a detailed evaluation and analysis of the multiple aspects involved is lacking. The aim of this paper is to identify and summarize the main aspects regarding the field of interoperability (strategic frameworks, laws, regulations, specific requirements, organizational and technical issues) by means of the location and assessment of works that focus on the identification and analysis of the barriers, issues and risk factors involved in IS corporate learning in public sector. The training model proposed and the project described are based on the analysis of several themes such as bond interconnection, information sharing, and processes integration between public European administrations.
\end{abstract}

Index Terms-Public sector, life long distance learning, change management, e-government.

\section{INTRODUCTION}

Interoperability is the capacity of information systems to process, store and exchange electronic documents using uniform technology standards and processes. In the age of the advanced information society, the interoperability of information systems of different organisations, both public and private, is a major factor in the efficiency of the economy. A number of European Commission directives indicate the crucial impact of this issue on the evolution of the information society and the EU Digital Agenda, one of the 7 flagships in the Europe 2020 strategy, defines interoperability as a main line of action. One of the question marks when addressing an objective as ground breaking as the interoperability is, "Are the necessary skills in place?" Whereas most European countries have developed excellent legislative frameworks and have set up the necessary institutions, the skills required of the players for the actual implementation of interoperability remain an obstacle. In the last five years were established several governmental programs, action plans, interoperability strategies, public sector IS frameworks. Besides quite a few public projects on interoperability issues, funded by the European Commission, the creation of observatories on e-government issues, and the increase in the number of conferences and scientific or practitioner associations focusing on the issue all, highlight the importance of interoperability for public organizations. However, despite this recognition and the investment and effort already made in the pursuit of improved collaboration and data exchange capacity between different government agencies, the level of interoperabil- ity between agencies remains far short of adequate and the problems and difficulties caused by this lack of interoperability are evident. Transparency means knowing the reasons, facts, and logics of the decision taken [1]. Unfortunately, public agencies continue to operate in a highly fragmented manner and delay in service delivery, lack of transparency regarding bureaucratic procedures, requiring filling out numerous application forms with identical sets or subsets of data.

\section{A MODEL FOR A NEW E-GOVERNMENT}

As part of the transparency and effectiveness of services, public administrations are obliged to adopt appropriate tools to detect customer opinions of its online services [2]. The subject of public CSM in public sector is particularly important at European level and has been treated in the European Primer on Customer Satisfaction Management, produced by EUPAN with the aim of providing countries with a set of methodologies and practices. The well-known evolution of the role of the State, from the New Public Management until the Governance approach, in its diverse interpretations, has been translated in a series of new principles and tools that characterize the Open Government Model. Open Government has been historically used in various contexts including freedom of information, anti-corruption, and transparency, so the concept cannot be considered recent. The U.S. government's strong initiative is getting, Open Government its new priority objective. The basic idea of Open Government is to establish a modern cooperation among politicians, public administration, industry and private citizens by enabling more transparency, participation and collaboration. Open Government is an interoperable government model in which people and systems can communicate easily. The role of ICT is central for opening government, though technology cannot explain all recent changes. Open Government Implementation Model (OGIM) needs of four specific implementation stages: increasing data transparency, improving open participation, enhancing open collaboration, realizing ubiquitous engagement.

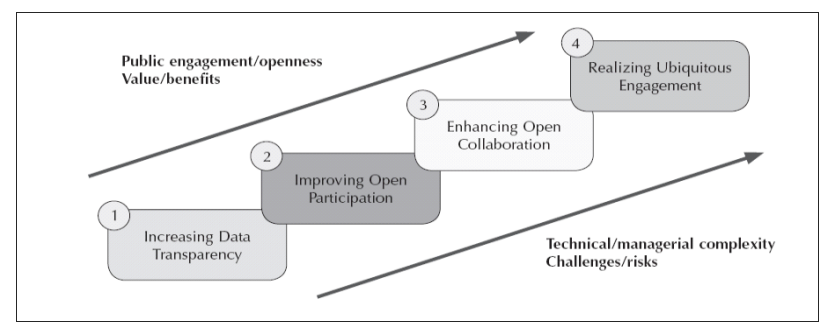

Figure 1. The Open Government Implementation Model 
The main key point of OGIM is that public authorities should advance their open government initiatives gradually, focusing on one implementation stage at a time. In fact, the increasing of data transparency is a required precondition and an enabler for implementing earlier phases. After all, without an accurate information management, it is not possible to establish a participation culture among the relevant stakeholders [3].

Transparency helps communities to enhance their governments by positive contributions, also helping to resolve concrete problems inherent specific government activities. Therefore, accessible information and Open Government Data (OGD) can be seen as crucial aspects of OGIM. Governments around the world are adopting massively information and communication technologies to increase efficiency and improve public sector services. Increasingly powerful and user-friendly technologies are creating serious opportunities for governments to offer new ways to interact with citizens in order to respond to their needs more effectively and with their integral participation. On the course of e-government development, Open Government Model and Government 2.0 seem to be, respectively, the new ends and new means of e-government. The current platforms and interoperability of technology-enabled public administrations are moving from a traditional egovernment approach (Government 1.0) to Open Government and Government 2.0 approach. This shift transparency has been increasingly emphasized as a fundamental driver for e-government. The development of online services has been studied at different stages: (1) presence, (2) integration, (3) transaction and (4) seamless that describe the new patterns of interactions of digital governments. These four stages are explained in terms of complexity involved and different levels of integration.

The last stage is reached when the government promotes shared governance to transform how it operates, in terms of seamless information flow and collaborative decision making. This is the most sophisticated level of online e-government initiatives and is characterized by:

- horizontal connections among public agencies;

- vertical connections (central and local);

- infrastructure connections and issues;

- relations between governments and citizens;

- influences among stakeholders (government, private sector, companies, etc.).

This last stage has not yet been fully achieved, since the transformation of government requires a meaningful negotiation between public administrations and citizens as well as among citizens themselves. Information should flow not only between public organizations and from the government to the citizens but also from citizens to the government and to citizens as a network. In order to achieve this kind of transformation, there needs to be extensive technology support for citizen participation [4]. In addition, the government needs to make sure to release information and to make it available to the public for informed discussions and participation. This will promote a collaborative decision making process by including citizens in the inception of new government policies called "Open Government Model". The Open Government initiative endorses transparency, participation, and collaboration that may offer new means for an electronically-mediated governance, sewing the gap between the actual status of e-gov-

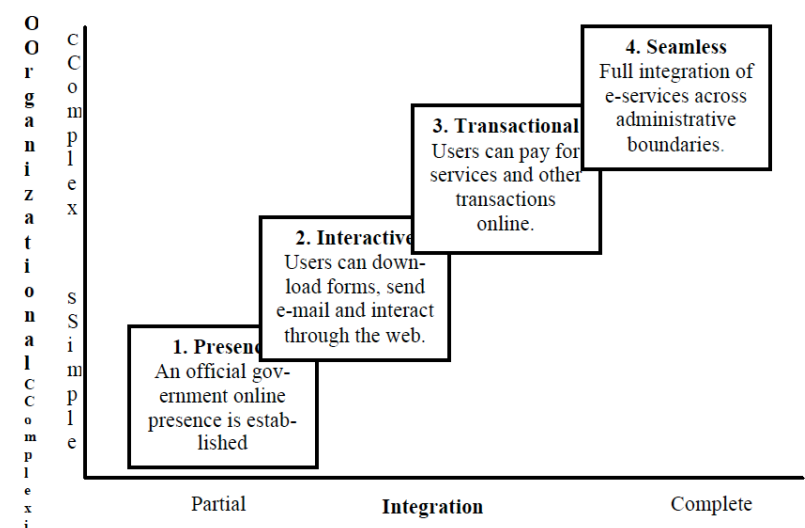

Figure 2. The stages of an effectiveness e-government development

ernment (use of e-government chiefly for cataloguing information on governmental webpages, web-based interaction and on-line transactional services) and the "seamless" stage of e-government. Consequently, Open Government Model is the new goal and Government 2.0 is new tool of e-government. Due to the increasing complexity of data required, the range of services to be provided and the heterogeneity of the public, differentiation between the channel options available to the customer is of prime importance [5]. The work of organization and integration of information supply is operated from a multi-level back office, which should not only select and implement the tools and communication channels, but also produce content that is tailored specifically to the publication medium. The criteria for selecting a channel and a tool are based on: accessibility, attractiveness, flexibility and adaptability to the location/service, cost/benefit analysis, innovation, delivery modes, diffusion of the instrument and the spacetime coverage. A further distinction of instruments may be: information tools, relational tools and settlement instruments [6]. The Public Connectivity System (PCS) is a network that interconnects all public administrations, enabling them to share and exchange data and information resources. The process of integration and data administration occurs by the availability of an architectural interface with which different systems and organizations are presented and exchange their data and services. Individuals, directors and employees of companies and Public Administrations can acquire a digital signature and managing the process of drafting, review and approval of documentation flows is completely customizable by the user, who can also organize documents in folders with hierarchical or logical links. The use of a workflow engine facilitates the development of specific modules. The process of managing Public Administration documents comprises transmission of files via computer, management of document flows to the proceedings and the record update management and archiving [7]. This is the collection and storage of all incoming documents (mail, email, fax) and the management of the entire process by contacting the offices concerned to create a "dossier". This minimizes paper documentation both internally and externally; stores and searches for any document type, including fax and e-mail; keeps an archive of previous versions of documents and simplifies the dissemination of information and documents. The needed reorganisation is essentially based on the need to respond to the objectives of improving the PA in terms of increased effectiveness of public action (effectiveness), containment of government operating costs and 
reducing the time needed to perform various activities (efficiency), increasing visibility and the possibility of user control (transparency). The concern over the issues of reengineering processes comes mainly from the observation of widespread problems encountered in public administration to define, initiate and implement computerization projects capable of achieving visible and tangible results in terms of improvement of services provided to citizens and cost-efficiency [8]. The initiative is aimed at developing a methodological proposal for the reengineering of service processes to be proposed to the government and in particular of a methodology:

- to supplement the current methodology for the threeyear planning of information systems;

- applicable in either scenario of radical change or minor improvement of existing processes;

- applicable to both interventions aimed primarily at restoring efficiency and actions aimed at improving the quality of services provided;

- flexible and adaptable to specific situations of the various administrations and, especially, scalable, i.e. applicable to areas of complex processes that often involve a plurality of administrations;

- pragmatic and results-oriented, used by the subjects of change, and able also to enrich the cultural heritage of the PA staff involved.

\section{AN EUROPEAN FUNDED PROJECT TO SPREAD THE INTEROPERABILITY CULTURE}

The ELGI "eLearning for e-government" project deals with the issue of interoperability in the context of egovernment and the establishment of cross-border electronic services (http://www.elgiproject.eu). It aims to improve the knowledge and skills of stakeholders in egovernment projects across Europe through the development of an innovative e-learning tool based on the consortium's own state-of-the-art research.

Skills and expertise are gathered from a variety of sources: research institutions, universities, VET, public administration cooperation, e-learning and interoperability. Each partner institution is a leading educational/training organization with a vast network extending between the target groups and the resources to disseminate and exploit results of the project effectively and efficiently [9]. The resulting e-course contributes to the inclusion of working adults in lifelong learning and the development of new skills and attitudes to help them meet the requirements of the changing environment, thereby improving their employment prospects. The objectives reached by the project are:

\section{An e-learning platform offering content aimed at:}

- understanding of the processes of entry in registers of information objects related to electronic services and all related operating instructions of National legislative bodies;

- ability to formulate unified names of electronic services and their status, to analyse the legal consistency and technological feasibility of electronic administrative services;

- awareness of the legal regulations and procedure needed to certify these software applications, for use in e-government and e-learning;

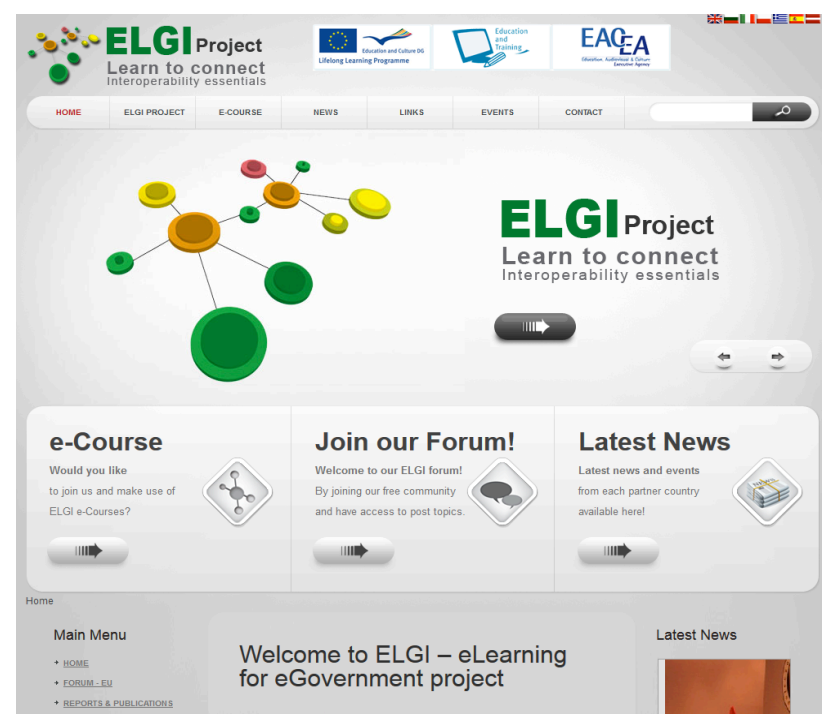

Figure 3. The EU project website: http://www.elgiproject.eu

- ability to formulate the processes of re-engineering of existing administrative systems so that they are eligible for certification, and to define adequate specifications for the creation of new systems in accordance with the law and regulations.

\section{Training of target groups:}

- civil servants of local, regional and national public administrations, national institutions, and agencies;

- managers of e-government projects;

- information systems developers;

- policy makers and citizens.

E-learning has been chosen as a training method for its three major advantages:

- in the field of interoperability, an electronic course promises to be most effective;

- proven cost-effectiveness;

- flexibility in terms of real time updates to the topics covered.

The project has the potential for playing an important role in the development of public services in Europe, both at national and local level and in support of broader crossnational needs [10]. The ELGI project was carried out in five phases: the first part focused on general information regarding the participant's Country by summarising the situation of citizens, companies and public administrations in order to identify the features of each Country involved in the project and understand the dimension and historical background in Public Sector. The second focuses in particular on the regulatory and legal aspects that already exist and any future legal amendments required to enhance online service interoperability of each Country involved. The third focuses on the organizational aspects and their effects on PA structures and on the performance of the services provided. The fourth deals with the technological aspects, detecting unsuccessful attempts and analysing the strengths and weaknesses of any given action.

The final phase comprises a detailed description of a successful example as best practice and an on-going experiment of interoperability in each Country. 


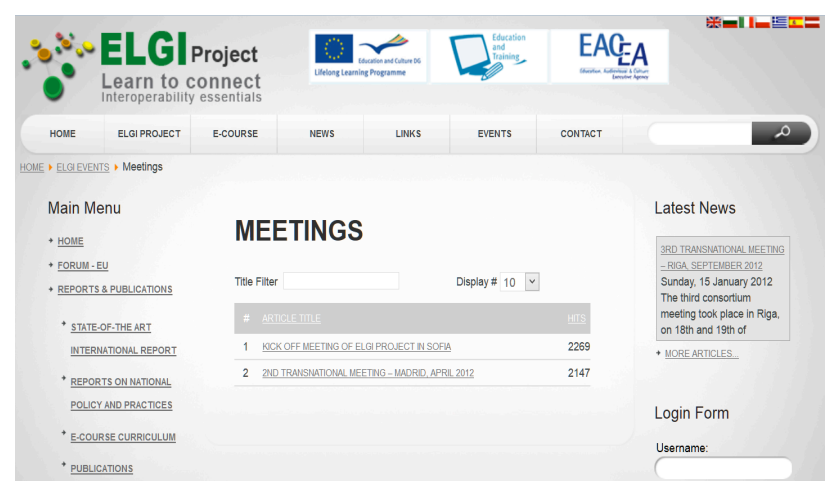

Figure 4. The meetings managing system

\section{THE EXPERIENCES ANALYZED}

The public administrations involved in interoperability training actions and investigated in the ELGI project include:

- AgID - National Body for the Digitalization of Public Administration: this body is governed by public law, has expertise in the field of information technology and communication within the Public Administration;

- Department for the digitalization of the public administration and technological innovation: this body is the facility used by the President of the Council of Ministers for the coordination and implementation of policies promoting the development of the Information Society, and related innovations;

- Formez PA: a public service center, offering support, studies and training for the modernization of Public Bodies;

- Infocamere: a consortium of information technology companies of the Italian Chambers of Commerce;

- CONSIP: a public company owned by the Ministry for the Economy and handles procurement on behalf of public administrations.

- The main systems adopted comprise:

- SPC: The Public Connection and Cooperation System is a complete system comprising technical communications infrastructure, services, a registry and connection rules and guidelines. SPC has already reached a mature stage and continues to evolve;

- SIOPE: the Information System on the Operations of Public Bodies, is a system of electronic tracking of receipts and payments made by the treasurers of all public bodies;

- SIATEL (Local Bodies Tax Registry Interchange System): by which public bodies can obtain taxpayers' fiscal domicile;

- SISTER (Inter-Territory Exchange system): offers cadastral and mortgage title search system. Local authorities can now access the database of the Agency of the Territory and check the tax base reported by citizens for the payment of municipal property tax or municipal solid waste disposal tax and check the owner of a property located within the territory;

- Telemaco: an online service developed by InfoCamere to give access to data regarding the Register of Companies held by the Chambers of Commerce and enabling certified online registration of firms, corporations and individual firms;

- INPS on line: information channel, developed to promote the digital handling and transmission of data regarding the recruitment and payment of employee contributions;

- Italia.gov.it: search engine and index of public websites, developed and managed by AgID. The purpose of the service is to facilitate the $\mathrm{G} 2 \mathrm{~B}$ and $\mathrm{G} 2 \mathrm{C}$ relationships;

- dati.gov.it: a web portal for data sharing between Public Administrations: this website is a compilation of recent information on the appropriate licenses designed to allow free circulation of data via the Italian open data license 2.0 and used by PAs to give access to the information contained in their websites;

- CEC-PAC: in order to make the services provided by the digitization of PA available, Certified Electronic Mail is an essential tool and therefore obligatory for all public authorities;

- SIT - Geographic Information System: is the system of obtaining and sharing data on a specific geographic area;

- Companies Register: provides online data regarding Italian and European companies, their shareholders and directors.

AgID coordinates the instruments and modernization procedures for the activities of PAs. This body has also established working groups to define the technical requirements and guidelines relating to strategic aspects of the process:

- creation of electronic documents, storage systems and management of document flows;

- digital identity management for data access;

- operational continuity and critical infrastructures.

\section{ORGANIZATIONAL ASPECTS AND ISSUES OF "LEARNING TO CONNECT"}

Monitoring, a form of quality control process related to administrative records in accordance with national regulations, must be undertaken within the context of a public process (competitions, announcements, contests, contracts, simpler administrative procedures) [11]. The "Measurement, evaluation and transparency of performance" section of Law 150/2009 provides the following dynamics for the performance management cycle.

TABLE I.

TYPE SIZES FOR CAMERA-READY PAPERS

\begin{tabular}{|l|l|}
\hline \multicolumn{1}{|c|}{ Phase } & \multicolumn{1}{|c|}{ Responsibility } \\
\hline $\begin{array}{l}\text { Identify the basic methodologies of } \\
\text { the cycle }\end{array}$ & Commission \\
\hline Political prioritization & Political-administrative \\
\hline $\begin{array}{l}\text { Translating operational priorities, } \\
\text { through the activities of management } \\
\text { and services for citizens }\end{array}$ & Executives and employees \\
\hline $\begin{array}{l}\text { Support of the development cycle of } \\
\text { performance management and ensure } \\
\text { the application of methodologies pre- } \\
\text { pared by the Commission }\end{array}$ & Independent evaluation body \\
\hline
\end{tabular}


The innovation of the Italian Public Administration, in addition to a total re-engineering of the entire procedural administrative apparatus, includes a new approach offered to citizens. There are several guidelines for the preparation of streamlining measures adopted by the Italian Government and for monitoring and evaluating the progress of these activities, time-keeping and effective achievement of objectives. Each administration has been considered as a structure with ad hoc indicators and gages [12]. This activity has revealed the existence of a number of critical procedures of a legal nature, including:

- the significant number of administrative tasks required by law;

- the multiplicity of authorities involved in individual cases;

- the diversity of tools such as simplification, authentication and log-in self-certification, silence gives consent;

- non-standard application forms in any local area;

- regional initiative in terms of computerization and telematics;

- unsatisfactory usage of digital administration solutions capable of improving levels of service.

The effects of critical opinions collected from the business sector that perceives as excessive are the:

- costs of access to informations;

- excessive time costs relating to bureaucracy.

- The new Plan for reducing administrative fees in Italy (2007-2012) provides some benefits such as:

- elimination of obsolete informations;

- elimination of duplications;

- standardization of forms;

- online procedures (less paper);

- reducing the frequency of compliance;

- reduction of administrative burdens and bureaucracy;

- reducing delays and inefficiencies generated by errors or delays in data management;

- number's reduction of civil servants.

One of the fundamental requirements of online communication in the Public Administration is to ensure maximum accessibility to information and full utilization of the services provided [13]. The Department for the Digitization of Public Administration and Centre for Technological Innovation has promoted accessibility to services provided by Public Administrations on line. This network improves responsiveness to citizens, promotes a unified perception of the system of the Italian PA, and develops confidence in public services, enhancing the professionalism of civil servants who work in contact with the public and those with back office roles who operate services. Access to administrative documents is one of the cornerstones of the administrative procedure jurisprudence and the measurement of the level of democratization of Public Administration. Online services enable citizens to apply for access to information and/or documentation on a variety of websites and consult announcements published in the Official Journal.

AgID intends to co-finance projects that involve the transfer of e-government solutions already implemented and in operation, so that other administrations can reuse the solution. The deployment of innovative technologies in Public Administration can only be deemed effective if its contribution to improving the final performance of the service provided to users is clearly perceived [14]. The proposed approach does not exclude the need to reorganize and innovate the back-office processes that lead to the final delivery of the service and requires that such reorganization be explicitly aimed at improving service to users. Participation, discussion and interaction with users form increasingly valuable elements, not only for citizens, but also for the administration body running the web site [15]. The main Front-end services are the following:

1. CSM (Customer Satisfaction Management): can greatly enhance the dialogue with users, as forms of interaction at various levels can be easily implemented.

2. RSS (Really Simple Syndication): used for the dual purpose of disseminating and aggregating content, making it particularly easy to use and ensuring interoperability across multiple platforms.

3. Web forms: the creation of CSM online forms to receive feedbacks from citizens or create special questionnaires, permits greater awareness of visitors and avoids the creation and publication of ad hoc email addresses potentially subject to spamming.

4. Newsletters: offer to Public Administrations the possibility of reaching a higher number of citizens.

5. Multilingual: a CSM easily manages content written in multiple languages, facilitating not only a rapid evolution between different features but also the translation of the entire interface of the site.

6. Content for mobile: the sharp increase in recent years of the use of enabled smartphones for consulting online contents should urge the PA to make information easily accessible.

7. Taxonomy: the accurate indexing of contents allows the user to reach information of interest more easily, increasing the availability of documents and easy reference to information.

In the last year, new goals were fixed as follow:

- the government allows users to make payments due to the government, with the exclusion taxes governed by specific regulations, by means information technology and communication;

- central government may use service providers for payments by debit, credit or prepaid cards and other electronic payment instruments available;

- all Regions and local authorities must be provided of systems for online payments.

\section{DESCRIPTION OF A MODEL FOR THE INTEROPERABILITY OF PUBLIC PROCESSES}

Public information systems include all features that support the storage, retrieval and maintenance of information supporting the public administrative services. Enterprise Resource Planning (ERP) is proven to significantly increase efficiency, improve information access, reduce total cost of ownership, and help government achieve the highest levels of accountability and constituent services [16]. Some important features that these organizations are integrating are the following:

MIS - ERP - Payroll / Personnel for Public Administration 
The main solution is the implementation of an Integrated Information System adapted for the public sector. Main subsystems of the applications are:

- financial management;

- public accounting;

- procurement;

- contract management;

- management of the projects

- decision support system;

- data processing;

- information analysis and reports.

HRM - Payroll. In this case, the subsystem supports organizations on issues such as:

- human resource management;

- recruitment;

- appointments;

- licenses;

- skills evaluation;

- issue of all types of payroll.

\section{Protocol and Document Management}

A software application for the creation, management, workflow and tracking of all types of electronic documents. AgID is the Public Administration organization delegated to the definition of standards, architecture and guidelines about the development of e-services in the Italian e-government domain. AgID is currently responsible for the entire lifecycle of the Public Connectivity System and Application Cooperation. A standard for XML representation of norms and a specific plan has been defined, with particular regard to the peculiarity of the structure of documents and metadata for advanced documents' management and workflow [17].

The model establishes two central principles:

- cooperation among administrations is exclusively carried out by its tools and according to its technical rules; it has legal value and no further decree or official publication is needed (e.g. standard XML formats for data exchange);

- public ICT managers need to organize their information systems, including organizational and management aspects, in order to accommodate workflow rules.

The European Union has a long history of promoting projects and standards that encourage the adoption of secure-authentication tools online. Each Member State is committed to enacting these initiatives by law and establishing a regulatory framework for the spread and use of these standards [18]. The model represents the most effective way to meet the requirements of the law for standardization and widespread adoption, unlike other exclusive authentication mechanisms. The spread of smartphones and other thin, networked devices offers the technological grounding for a capillary distribution of this solution and for its efficient management. The role of e-government in treating information as a key service to the citizen becomes increasingly important and lends credence and significance to the need for maintenance and sustainability of online service delivery [19]. Over recent years the number and dimension of Public Administration websites have in-

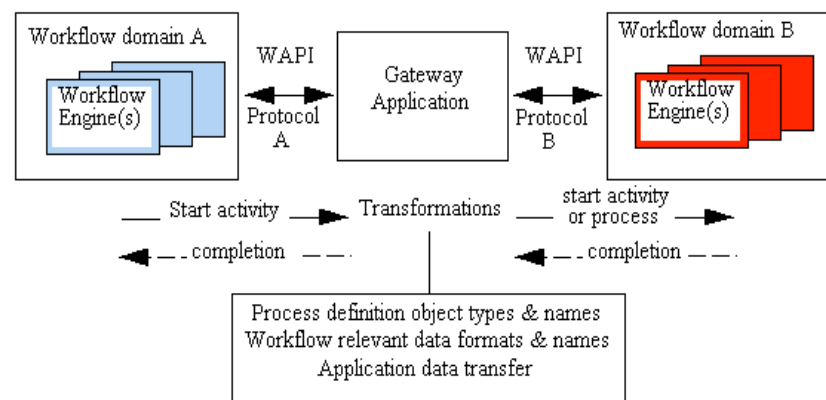

Figure 5. An example of relation between the application and the workflow domains

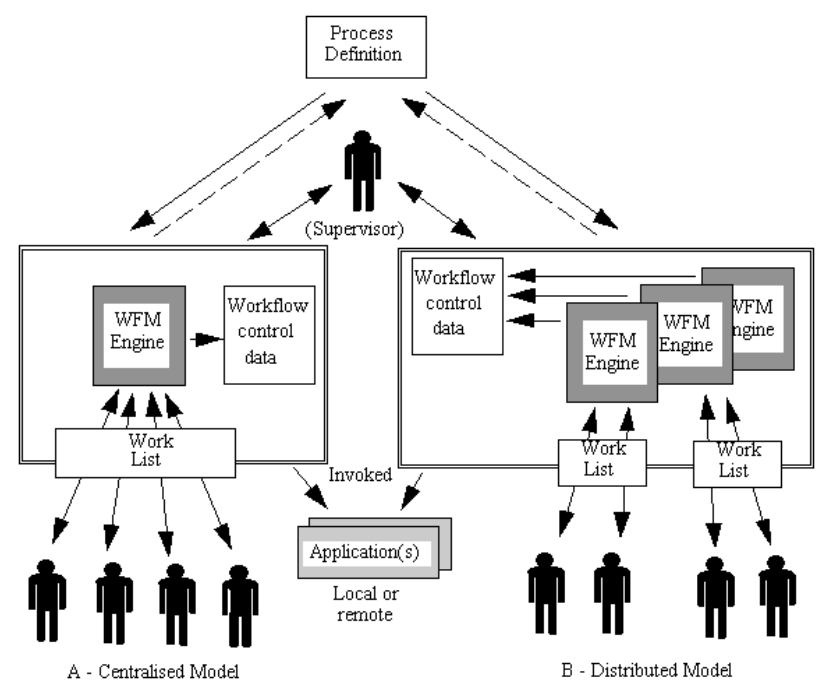

Figure 6. An example of organizational situations (centralized and distributed) for workflow and processes control

creased at such an impressive pace that the daily monitoring of the information has proved increasingly complex, both quantity- and quality-wise [20]. Moreover, in terms of their complexity and economical and planning efforts, the investments of public sector turn out to be comparable with those of the most advanced private sector organisations. The borders between services for citizens, businesses and professionals are more and more undefined. At present, online web-services are not the only integration technology available on the market. At present, within main public organizations, situations characterized by substantial innovation co-exist with situations in which progress towards innovation are still hampered by substantial obstacles [21]. The reform's process, aiming at the modernisation of the Public Administration and based on centralized model, is focused on:

- promotion of the effectiveness;

- impact on competitive sourcing models;

- alignment of collective bargaining provisions;

- importance of effective managerial way of thinking for civil servants;

- simplification of WFMS and document management.

The key idea is that available state-of-the art technologies in the fields of information retrieval, natural language processing, semantics and machine learning are now adequate to build a common knowledge management system (KMS) capable of collecting and automatically managing large quantities of data and information to a level of quali- 
ty (in terms of correctness and completeness) comparable or higher than human teams could reach. This innovative approach to the development of e-government portals collects and provides information gathered from a number of different, heterogeneous, independent sites in a consistent way [22]. The DB system, from the point of view of software architecture consists of a database (MySQL) containing data and a web application for maintenance (research, creation, update, removal). The options for sharing data, adding information to the master data or simply restating data, can be summarised as follows:

- extended rules of the DB;

- direct access to the DB (read only);

- applications integration.

\section{CONCLUSIONS}

The centralized approach to the governance of public information systems and services could be easily replicated in other countries as well. This approach is being applied in the framework of ELGI project aimed at the establishment of a training system for civil servants.

Public organizations choose appropriate services (IP multi-channel services, VoIP services, security services, etc.), to connect their offices from a special list managed by AgID. The first significant impact is the costs' saving (approximately 50\%). Furthermore, the quality and security of public services have been improved. The project (on December 2013) involves 56 central PAs (over 20000 websites connected), 20 regions, 110 provinces and 8000 municipalities. The case developed is an innovative multiprovider model that promotes competition between ICT providers. All the qualified providers will be connected to the qualified exchange network made of different neutral access points and managed by AgID through a specific consortium. In order to implement their networks, the PAs choose the appropriate services from a list. The network is already operational and almost all ministries have deployed their networks and activated the main services on their websites. Several new services are planned such as the Electronic Visa and the Electronic Passport (for Ministry of Foreign Affairs). China and other Mediterranean countries showed a strong interest on the project along with LINX of London, which is investigating a possible deployment for the English Government. The proficiency and the cost reduction of ICT services is a clear benefit not only for PAs but also has a knock-on effect for other sectors such as finance, industry etc. This would make it possible to determine how the complex of forces acting on each country can be related, for example, with the existence of previous ICT structures, with the presence of partnerships with private/public institutions, with the attitude of PA civil servants, and with specific organizational issues. Similar training experiences in other countries will provide different levels of development and maturity on egovernment services, particularly with respect to the level of interoperability between PA, and can improve the operations of the public information systems [23], achieving and providing great benefits for civil servants and citizens.

\section{REFERENCES}

[1] N. Casalino, A. D'Atri, A.M. Braccini, “A management training system on ISO standards for organisational change in SMEs", International Journal of Productivity and Quality Management (IJPQM), Inderscience Publishers, USA, vol.9 is. 1, 2012.
[2] M.A. Winner, Integrated Service Modelling for Online One-stop Government, vol. 12, 3, pp.149-156, 2002.

[3] A. Carneiro, "How does knowledge management influence innovation and competitiveness?", Journal of Knowledge Management, vol. 4, no. 2, pp.87-98, 2000. http://dx.doi.org/10.1108/ 13673270010372242

[4] S.M. Kaplan, "Discontinuous innovation and the growth paradox", Strategy and Leadership, March-April, pp. 16-21, 1999. http://dx.doi.org/10.1108/eb054631

[5] P. Birkinshaw, "Freedom of information", Parliamentary Affairs, 50, 1, pp.164-181, 1997. http://dx.doi.org/10.1093/oxfordjournals. pa.a028711

[6] N. Casalino, "An Innovative Model of Transnational Learning Environment for European Senior Civil Servants - Organizational Aspects and Governance", proceedings of 11th International Conference on Enterprise Information Systems - ICEIS, INSTICC, pp.148-153, 2009.

[7] M. Khosrow-Pour, N. Herman, "Critical issues of Web-enabled technologies in modern organizations", The Electronic Library, vol. 19, no. 4, pp.208-220, 2001. http://dx.doi.org/10.1108/ EUM0000000005745

[8] G. Lee, Y.H. Kwak, An Open Government Implementation Model, Using Technology Series, Washington, 2011.

[9] J. Butler, "A practical model for technology and innovation management", Proceedings of the Portland International Conference on Management of Engineering and Technology, PICMET, pp.103-105, 1999.

[10] R.P. Dameri, C. Benevolo, C. Rossignoli, F. Ricciardi, M. De Marco, "Centralization vs. Decentralization of Purchasing in the Public Sector: The Role of e-Procurement in the Italian Case", in Lecture Notes in Computer Science, V. Khachidze et al. eds., Berlin, Springer-Verlag, pp.457-470, 2012.

[11] H. Chesbrough, "The New Business Logic of Open Innovation", in Strategy \& Innovation, 1, pp.11-15, 2003.

[12] S. Dawes, "Stewardship and usefulness: Policy principles for information-based transparency", in Government Information Quarterly, 27, 4, pp.377-383, 2010. http://dx.doi.org/10.1016/ j.giq.2010.07.001

[13] H. Darbishire, Proactive Transparency: The future of the right to information? A review of standards, challenges, and opportunities, Washington, MA, WBI, pp.1-60, 2009.

[14] Z. Jin, "Organizational innovation and virtual institutes", in Journal of Knowledge Management, vol. 3, no. 1, pp. 75-83, 1999.

[15] E.H. Kessler, A.K. Chakrabarti, "Methods for improving the quality of new product innovations", Proceedings of the Portland International Conference on Management and Technology, PICMET, pp.405-408, 1997.

[16] P. Miller, "Interoperability: What is it and why should I want it?" Ariadne Magazine, 2000.

[17] S.A.Chun, S. Shulman, R. Sandoval, E. Hovy, "Government 2.0: Making connections between citizens, data and government", Information Polity, 15, pp.1-9, 2010.

[18] H.A. Simon, "Applying Information Technology to Organization Design”, Public Administration Review, 33(3), pp.268-278, 1973. http://dx.doi.org/10.2307/974804

[19] D. Soares, L. Amaral, "Information Systems Interoperability in Public Administration: Identifying the Major Acting Forces through a Delphi Study", in Journal of Theoretical and Applied Electronic Commerce Research, vol. 6, is. 1, pp. 61-94, 2011.

[20] S. Dawes, "Interagency Information Sharing: Expected Benefits, Manageable Risks", in Journal of Policy Analysis and Management, vol. 15, no. 3, pp.377-394, 1996. http://dx.doi.org/10.1002/ (SICI)1520-6688(199622)15:3<377::AID-PAM3>3.0.CO;2-F

[21] M. Sorrentino, "Interpreting E-Government: Implementation as the Moment of Truth", in Winner M., Scholl H. J., Grönlund A. (Eds.), EGOV 2007 Lecture Notes in Computer Science, Berlin Heidelberg, Springer-Verlag, pp.281-292, 2007.

[22] N. Casalino, S. Armenia, D. Canini, "A system dynamics approach to the paper dematerialization process in the Italian public administration", in The Interdisciplinary Aspects of Information Systems Studies, D’Atri A., De Marco M., Casalino N. Eds., ItAIS, Physica-Verlag, Springer, Heidelberg, Germany, pp. 399$408,2008$. 
[23] C. Ciborra, "Interpreting e-government and development: Efficiency, transparency or governance at a distance?" in Information Technology \& People, vol.8, no. 3, pp.260-279, 2005. http://dx.doi.org/10.1108/09593840510615879

\section{AUTHORS}

N. Casalino is Associate Professor of Business Organization and Human Resource Management as well as Director of Master in Business Administration and Master in Human Resources and Organization at Guglielmo Marconi University - Department of Business Strategy and Innovation. He obtains a Ph.D. in Business Information Systems Management at LUISS Guido Carli University. His research interest areas are in Business Organization and Human Resource Management, Corporate learning, Egovernment, Enterprise Resource Planning, Computer Supported Collaborative Work and Groupware Systems. $\mathrm{He}$ is Director of Centre for Studies and Research on the Economy of the Networks and New Professionals (CERP) at Guglielmo Marconi University, Rome, Italy (e-mail: n.casalino@unimarconi.it).

This work was supported by the European Commission by Lifelong Learning Programme 2007-2013, Leonardo da Vinci Programme - Action: Development of Innovation under grant LdV ID: 518366-LLP2011-BG-LEONARDO-LMP, "ELGI - eLearning for eGovernment". Submitted17 February 2014. Published as re-submitted by the author 04 April 2014. 